\title{
The Role of Matrix Metalloproteinases in Human Body
}

\author{
Hafiz Hasanov ", Khayala Mammadova, Firangiz Guliyeva, Ulviya Azizova and Nigar Mikailova
}

Department of Biochemistry, Azerbaijan Medical University, Azerbaijan

\begin{abstract}
MMPs are $\mathrm{Zn}$ dependent proteases. All of MMPs kind is multi-domain proteins and their activities are regulated by tissue inhibitors of metalloproteinases. The prevention of the pathologies which is created by MMPs used some synthetic and naturally inhibitors. This review will explain the attitude MMPs and some chemical and physical factors which to being high level and low could affect to MMPs activity and synthesis as caffeine, one of snake venom components, melatonin, serotonin, stress factor, $\mathrm{E}$ and $\mathrm{C}$ vitamins.
\end{abstract}

Keywords: Enzyme; Cardiovascular diseases; Rheumatoid arthritis; Suprachiasmatic nucleus

\section{INTRODUCTION}

Matrix Metalloproteinase enzymes (MMPs) were discovered, in 1962, by Jerome Gross and Charles M. Lapierre while studying the degradation of triple-helical collagen during the metamorphosis of a tadpole tail. The collagen was cleaved by an enzyme known as interstitial collagenase. This enzyme was first isolated from human skin in the inactive form, pro-MMP (also called MMP zymogen), in 1968. It was later found in both invertebrates and plants. In 1990, it was discovered a cysteine switch mechanism was responsible for regulating the enzyme in its inactive form. After the complete sequencing of the human genome, it was determined that twenty-four different genes encoded a set of all human MMPs. MMPs are $\mathrm{Zn}$ dependent proteases. MMPs have 27 types and each type has a special character. MMPs also called matrixinis [1]. MMPs play big role in morphogenesis, embryonic development, embryonic invasion to endometrium, renew extracellular matrix elements, wound healing, tissue repair, and remodeling of new tissue after myocardial infarction and MMPs also participate progression of disease such as rheumatoid arthritis, caries, cardiovascular diseases, atherosclerosis, Parkinson, Alzheimer diseases, atheroma, cancer, metastasis. All of MMPs kind is multi-domain proteins and their activities are regulated by tissue inhibitor of metalloproteinase. The prevention of the pathologies which is created by MMPs used some synthetic and naturally inhibitors This review will explain to reader attitude MMPs and some chemical and physical factor which there to being high level and low could affect to MMPs activity and synthesis as caffeine one of snake venom components, melatonin, serotonin, stress factor, $\mathrm{E}$ and $\mathrm{C}$ vitamins.

\section{THE ROLE OF VITAMIN C AND E IN MMPs INACTIVITY}

Oxygen free radicals are very reactive molecules which can react with every cellular component. They are normally produced in organisms being involved in various biological reactions. However, too high levels of these partially-reduced $\mathrm{O}_{2}$ species can give rise to functional and morphologic disturbances in cells. There is evidence to implicate oxygen free radicals as important pathologic mediators in many human disease processes. Oxygen free radicals are very reactive molecules which can react with every cellular component. They are normally produced in organisms being involved in various biological reactions. However, too high levels of these partially reduced $\mathrm{O}_{2}$ species can give rise to functional and morphologic disturbances in cells [2]. There is evidence to implicate oxygen free radicals as important pathologic mediators in many human disease processes such as $\mathrm{O}_{2}$ free radicals take part actively in activities of MMPs enzyme. Vitamin $\mathrm{C}$ and $\mathrm{E}$ rendered harmless $\mathrm{O}_{2}$ free radicals and eliminate from the organism. Therefore for prevention of MMPs pathologically affect it is well to use vitamin therapy [3]. Injection of $\mathrm{C}$ and $\mathrm{E}$ vitamins together to the organism gives the best effect because of vitamin $\mathrm{C}$ protects the structure of vitamin E. Vitamin $\mathrm{C}$ takes part in the absorption folic acid from the intestines or in the collagen synthesis as the helper for immune system, also vitamin $\mathrm{C}$ renders harmless $\mathrm{O}_{2}$

*Corresponding author: Hafiz Hasanov, Department of Biochemistry, Azerbaijan Medical University, Azerbaijan; E-mail: xayale81@yahoo.com

Received date: December 3, 2018; Accepted date: December 21, 2018; Published date: December 28, 2018

Citation: Hasanov H, Mammadova K, Guliyeva F, Azizova U, Mikailova N (2018) The Role of Matrix Metalloproteinases in Human Body. Biol Med (Aligarh) 11:452. doi:10.35248/0974-8369.19.11.452.

Copyright: (C) 2018 Hasanov H, et al. This is an open-access article distributed under the terms of the Creative Commons Attribution License, which permits unrestricted use, distribution and reproduction in any medium, provided the original author and source are credited. 
free radicals and reduces cancer risk [4]. The deficit of vitamin E, tocopherol resulted (tocos mean generation) the spermatogenesis disorder in the man while the naturally abort in the women. An $\mathrm{O}_{2}$ radical bind to the unsaturated fatty acid and replace double bond to the single bond then increases the membrane permeability and disrupted the work of the pumps. Vitamin $\mathrm{E}$ renders harmless $\mathrm{O}_{2}$ radicals and protects the membrane structure. Thus, the decontamination of the radicals prevents MMPs activity which reduces in future the cancer risk [5].

\section{THE RELATION BETWEEN MELATONIN AND MMPs ENZYME}

Melatonin, a hormone produced primarily by the pineal gland, is also secreted from the gut and eye during darkness. There are three classes of melatonin receptors, MT 1, MT 2, and MT 3, in various regions of the human brain, gut, ovaries, and blood vessels, but most consistently found in the Suprachiasmatic Nucleus (SCN) of the hypothalamus and the pars tuberalis of the anterior pituitary. Melatonin has endocrine, autocrine, and paracrine actions, which are mostly receptor mediated. Primary clinical uses include the regulation of circadian rhythms and sleep disorders, although it has anther endocrine and immunomodulatory effects [6]. Melatonin is synthesized from the serotonin at night and the basic structure element is the tryptophan. It is proved from the experiments that melatonin stimulated the thymus glandular work and this is the number one helper for decontamination $\mathrm{OH}$ radicals which is considered more danger among $\mathrm{O}_{2}$ free radicals. Generally, melatonin is the strongest antioxidant compound. Due to decontamination for $\mathrm{OH}$ radicals, it is affected against to MMPs [7].

\section{THE RELATION BETWEEN CAFFEINE AND MMPs}

Caffeine (1,3,7-trimethylxanthine) is a natural alkaloid found in coffee beans, tea leaves, cocoa beans, cola nuts, and other plants. It is probably the most frequently ingested pharmacologically active substance in the world, found in common beverages (coffee, tea, and soft drinks), products containing cocoa or chocolate, and medications, including a headache or pain remedies and over-the-counter stimulants [8].

Caffeine increases the motive force, the heart rhythms, the work of the organs and tissues, also thymus glandular, increases adrenaline hormone. Caffeine is absorbed in the stomach. The primary metabolism place is in the liver. But the uptake of the caffeine more than norm resulted in anxiety, headache, vomit, tachycardia, diarrhea, and arrhythmia. Caffeine disturbs the way of the synthesis of MMPs and decreases the quantity of MMPs enzyme [9].

\section{THE DEPENDENCE BETWEEN THE STRESS AND MMPs}

Stress is a normal emotion in the human organism which is able to help us to overcome dangerous situations or something like that. Also, stress is initiated of the several diseases. During stress, the synthesis of the glucocorticoids increases. Hippocampus and amygdala have receptors of the glucocorticoids; here occurs the connection of the ligand and receptor [10]. During heavy stress in these areas happened the atrophy of the dendrites. The stress causes increasing of the enzymatical reactions. The reason for the temporary or standing memory pathologies after the stress is these factors. During stress in connection with the increasing enzymatically reactions the quantity of the free radicals of $\mathrm{O}_{2}$ also increases [11]. In conclusion, the quantity of MMPs enzyme increases and stimulated the beginning pathologically processes. It is investigated the caries development under the stress effect. It has proved that the increasing of MMPs stimulated the development of caries [12].

\section{OMEGA-3 FATTY ACIDS AND MMPs}

Omega-3 fatty acids are the nutrient element which is important for the development and the growth of the organism. During the deficit occur the sluggish growth, vision disturbance, weakness in the learning and in the perception, irregularity in motor movements and behavioral changes. Omega-3 has the essential in the synaptogenesis and myelogenesis [13]. During damages in the brain, the uptake of the omega-3 shows the good effect. Because during damages of brain $\mathrm{T}$ killers will increase here and will release to this place MMPs, in conclusion in the nervous center happens incurable diseases (for example disturbed blood-brain barrier). During uptake of Omega-3 fatty acids, the activity of $\mathrm{T}$ (killer) cells decreases and this risk is delayed [14].

\section{COMPONENT OF SNAKE VENOM (BJ46A) AND MMPs}

Snake venom consists of more than 150 peptides, enzymes, and amino acids. Snake venom acute depends on the snake sort, age and the life areal. The influence of the different snake's venom differs for their specificity. For example, the cobra venom paralyzes the connection of the central nervous system while the viper venom clots blood. Snake venom is used widely in the pharmacology. Some important elements which included to the composition of the snake venom are isolated for the medicinal purpose. The BJ46a compound which belongs to the composition of the snake venom has inhibition effect; it inhibits MMPs which is activated in cancer metastasis [15].

\section{CONCLUSION}

Vitamin $\mathrm{C}$ and $\mathrm{E}$ is an inhibitor of $\mathrm{O}_{2}$ free radicals which is an activator of MMPs. Therefore these vitamins are important to prevent the activity of MMPs.

Melatonin could occur only at night from serotonin which is the strongest antioxidant in our body. The basic effect of Melatonin to MMPs is to doing inactivate of $\mathrm{OH}$ radicals which $\mathrm{OH}$ radicals are the most dangerous radicals for the human body.

The normal amount of Caffeine is useful for the human body which has the same pleasant function as disturbing MMPs synthesis. The basic effect of stress on MMPs is to increase $\mathrm{O}_{2}$ free radicals basically in the brain and in conclusion these radicals will activate MMPs. 
The basic mechanism of omega-3 fatty acid in injured brain is to decrease immune system cells in this area which these cells could release from itself some activators of MMPs and also itself of MMPs.

There is over 150 chemically component in snake venom which one of them is toxin, others is pharmacological useful as BJ46 which is a strong inhibitor of MMPs.

\section{REFERENCES}

1. Nagase H, Visse R, Murphy G. Structure and function of matrix metalloproteinases and TIMPs. Cardiovasc Res. 2006;69(3): 562-573.

2. Martínez-Cayuela M. Oxygen free radicals and human disease. Biochimie. 1995;77(3):147-161.

3. Hantke B, Lahmann C, Venzke K, Fischer T, Kocourek A, Windsor LJ, et al. Influence of flavonoids and vitamins on the MMP and TIMP-expression of human dermal fibroblasts after UVA irradiation. Photochem Photobiol Sci. 2002;1(10):826-833.

4. Orbe J, Rodríguez JA, Arias R, Belzunce M, Nespereira B, PérezIlzarbe $M$, et al. Antioxidant vitamins increase the collagen content and reduce MMP-1 in a porcine model of atherosclerosis: implications for plaque stabilization. Atherosclerosis. 2003;167(1): 45-53.

5. Kunwar A, Priyadarsini KI. Free radicals, oxidative stress and importance of antioxidants in human health. J Med Allied Sci. 2011;1(2):53-60.

6. Omar SH, Nabi S. Melatonin, Receptors, Mechanism, and Uses. Systematic Reviews in Pharmacy. 2010;1(2):158-171.

7. Ganguly K, Maity P, Reiter RJ, Swarnakar S. Effect of melatonin on secreted and induced matrix metalloproteinase- 9 and -2 activity during prevention of indomethacin-induced gastric ulcer. J Pineal Res. 2005;39(3):307-315.

8. Nawrot P, Jordan S, Eastwood J, Rotstein J, Hugenholtz J, Feeley M. Effect of caffeine on human health. Food Addit Contam. 2003;20(1):1-30.

9. Liu WH, Chang LS. Caffeine induces matrix metalloproteinase-2 (MMP-2) and MMP-9 down-regulation in human leukemia U937 cells via $\mathrm{Ca} 2+/ \mathrm{ROS}-m e d i a t e d$ suppression of $\mathrm{ERK} / \mathrm{c}$-fos pathway and activation of p38 MAPK/c-jun pathway. J Cell Physiol. 2010;224(3):775-785.

10. Yang EV, Bane CM, MacCallum RC, Kiecolt-Glaser JK, Malarkey WB, Glaser R, et al. Stress-related modulation of matrix metalloproteinase expression. J Neuroimmunol. 2002;133(1-2): 144-150.

11. Ali MA, Schulz R. Activation of MMP-2 as a key event in oxidative stress injury to the heart. Frontiers in Bioscience (Landmark Edition). 2009;1(14):699-716.

12. Chaussain-Miller C, Fioretti F, Goldberg M, Menashi S. The role of matrix metalloproteinases (MMPs) in human caries, J Dent Res. 2006;85(1):22-32.

13. Shinto L, Marracci G, Bumgarner L, Yadav V. The Effects of Omega-3 Fatty Acids on Matrix Metalloproteinase-9 Production and Cell Migration in Human Immune Cells: Implications for Multiple Sclerosis. Autoimmune Dis. 2011;2011:1-6.

14. Shinto L, Marracci G, Baldauf-Wagner S, Strehlow A, Yadav V, Stuber L, et al. Omega-3 fatty acid supplementation decreases matrix metalloproteinase-9 production in relapsingremitting multiple sclerosis. Prostaglandins, Leukotrienes and Essential Fatty Acids. 2009;80(2-3):131-136.

15. Morais-Zani KD, Grego KF, Tanaka AS. Proteomic Analysis of the Ontogenetic Variability in Plasma Composition of Juvenile and Adult Bothrops jararaca Snakes. Int J Proteomics. 2013;2013:9. 